\title{
EL VALOR PATRIMONIAL DE LOS PAISAJES RURALES. ALGUNOS EJEMPLOS*
}

\author{
Juan Ignacio Plaza Gutiérrez \\ Departamento de Geografía. Universidad de Salamanca
}

\section{RESUMEN}

Tras profundizar, inicialmente, en los significados y trascendencia que alcanzan conceptos y referencias como los de paisaje rural, paisaje cultural, patrimonio y territorio, a modo de contexto necesario, sin olvidar la importante apoyatura que tienen los procesos históricos en este marco, esta contribución pretende subrayar el valor patrimonial que define a los paisajes rurales. Para ello, procede a realizar un rápido repaso a determinadas referencias normativas y documentales más significativas en que se reafirma tal valoración y se apoya, asimismo, en algunos ejemplos considerados como especialmente representativos.

Palabras clave: Paisaje Rural, Paisaje Cultural, Territorio, Patrimonio.

\section{ABSTRACT}

The hereditary value of rurals landscapes. Some examples

After to go more deeply, initially, into the meaning and significance reaching concepts and references as the rural landscape, cultural landscape, heritage and territory, as a necessary context, without forgetting the important support that have the historical processes in this context, this contribution wants to highlight the heritage value that defines to rural landscapes. For that, it proceeds to make a quick review of some more

\footnotetext{
*Esta aportación se inscribe en los resultados derivados del Proyecto de Investigación «PAISAJES PATRIMONIALES DE LA ESPAÑA INTERIOR SEPTENTRIONAL Y OCCIDENTAL», referencia CSO2012-39564-C07-01, financiado por el Ministerio de Economía y Competitividad (MINECO). Dirección General de Investigación, Subdirección General de Proyectos de Investigación, Programa Nacional de Investigación, Plan Nacional de I+D+I, dirigido por el Dr. D. Fernando Molinero Hernando.
} 
significant regulatory and documentary references that such assessment is reaffirmed and also supports some examples considered as particularly representative.

Key Words: Rural Landscape, Cultural Landscape, Territory, Heritage

\section{INTRODUCCIÓN. PAISAJE RURAL, PAISAJE CULTURAL Y VALOR PATRIMONIAL}

Los paisajes rurales o los paisajes agrarios han constituido una referencia central de la Geografía desde las aportaciones que ya al final de la década de los años 50 del pasado siglo xx hiciera la Geografía francesa y, particularmente, autores como Meynier, continuadas posteriormente por obras como la de Lebeau, cada uno con su perspectiva. Aunque no es menos cierto que ya antes de la aparición de los trabajos de Meynier y Lebeau sistematizando el estudio de los paisajes agrarios, la Geografía francesa había ido avanzando mucho en este terreno ${ }^{1}$, tal y como se recogía en la publicación que, a modo de balance desde la década de los años 30, apareció en el número 17 (1957) de la revista Annales de l'Est firmada, además de por el propio Meynier, por otros geógrafos de renombre como Juillard, Planhol y Sautter, centrada en el significativo tema de «estructuras agrarias y paisajes rurales». Las cuestiones morfológicas y estructurales constituyeron sus argumentos centrales.

La descripción, modelización y tipificación que hicieron de tales paisajes abrió una fecunda tradición y línea de estudio traducida, además, en contribuciones que crearon escuela en otros países (la AGE publicó a principios de los años 80 la obra colectiva Los paisajes rurales de España, resultado de un ciclo de conferencias y debates centrados en esta temática, pero ya antes, los años 60 y 70 conocieron una rica eclosión de tesis doctorales que siguieron esta vía: la del profesor Cabo Alonso -1960- sobre el paisaje agrario salmantino, la de Gil Olcina -1967- sobre el Campo de Lorca, la de Torres Luna -1967- sobre la Navarra húmeda del Noroeste, la de Morales Gil -1972- sobre el Altiplano Jumilla-Yecla, la de López Ontiveros -1973- sobre la Campiña de Córdoba, la de Gómez Mendoza -1974- sobre la Campiña del Bajo Henares, la de Frutos Mejías -1975- sobre el Campo de Zaragoza, la de Rodríguez Martínez -1975sobre la Serranía de Ronda, la de Cabero Diéguez -1976- sobre La Cabrera, la de Ortega Cantero -1977- sobre las Vegas Bajas del Guadiana, o la de Molinero Hernando -1979- sobre la Tierra de Roa).

$\mathrm{Y}$ aún en nuestros días, la investigación y revisión de los conceptos y tipos que pueden diferenciarse en el estudio de un objeto tan central ha tenido

1. Lebeau, de hecho, definió en su obra ocho grandes tipos o conjuntos de paisajes agrarios existentes en Europa pero a partir de los trabajos de Derruau y de Birot, como muy bien recuerda Molinero (2011:6-7). 
continuidad y resultados modélicos (Atlas de los paisajes agrarios de España, producto editorial de los proyectos de investigación coordinados por el profesor Molinero, de la Universidad de Valladolid²). Sin desmerecer ni minusvalorar otros enfoques y perspectivas metodológicas en el estudio de los espacios rurales, no cabe duda que su disección y conocimiento a través de la identificación y descripción de los diferentes tipos de paisajes generados ha constituido y constituye un procedimiento básico y fundamental, de una gran relevancia.

La descripción, el análisis y el estudio del medio rural encontró en el paisaje, como expresión plástica, visual y estética más representativa, la herramienta o instrumento más definitorio y significativo para definir y comprender integralmente estos territorios de dominante agraria. En la base de esta tradición y línea de investigación encontramos, asimismo, la función tan destacada que han ejercido y ejercen los procesos históricos, desarrollados y protagonizados por las sociedades que han ocupado y explotado el espacio secularmente, en la configuración de los paisajes rurales, junto con el peso importante de las estructuras físicas o ecológicas. Una relación, esta que se establece entre procesos históricos y paisajes culturales, que, como bien han subrayado algunos trabajos (Fernández Cacho et al., 2010:66), el propio Consejo de Europa ya definía de forma explícita mediante su recomendación orientada para la aplicación del Convenio Europeo del Paisaje ${ }^{3}$. Nada de nuevo ni de extraño hay en esta idea, pues si nos remitimos, otra vez, a una de las obras referentes que al principio se señalaba, la de R. Lebeau sobre los grandes modelos de estructuras agrarias en el mundo publicada en 1979, este argumento se convertía en una referencia de contexto y principal reafirmada desde el principio, subrayando relaciones, elementos y formas como dimensiones fundamentales para entender

2. Ya en la página web del Grupo de Trabajo de Geografía Rural de la Asociación de Geógrafos Españoles (AGE), en su sección sobre el perfil, la trayectoria y las orientaciones del mismo, se insiste en esta misma idea al afirmar que «muchos ruralistas españoles continúan trabajando sobre temas de interés tradicional, que son, por descontado, todavía de actualidad. Es así como, por ejemplo, con perspectivas renovadas y orientaciones plurales, el tema de los paisajes rurales sigue constituyendo un referente que sobresale; quizá el testimonio más evidente y reciente a este respecto lo represente la publicación sobre Los paisajes agrarios de España, editada en 2011 por el que fuera Ministerio de Medio Ambiente y Medio Rural y Marino y coordinada por los profesores Fernando Molinero, Juan Francisco Ojeda y Joan Tort» (http://www.grupodegeografiarural.es/Grupo_geografia_rural/Perfil_evolucion_orientacionesGrupoGeografiaRural.pdf, pg. 2)

3. CONSEJO DE EUROPA (2008). Recomendación CM/Rec(2008)3 del Comité de Ministros a los Estados miembro sobre las orientaciones para la aplicación del Convenio Europeo del Paisaje. Estrasburgo. En ella se remarca que el proceso de identificación y caracterización de los paisajes ha de comprender, entre otros criterios que también detalla, «el análisis de los procesos evolutivos y la constatación de las dinámicas temporales pasadas, presentes y previsibles derivadas de factores humanos o naturales así como de las posibles presiones que se ejercen sobre los paisajes y los riesgos que pueden resultar de ello» (art.II.2.1.). 
la estructuras y los paisajes agrarios ${ }^{4}$. Un planteamiento que, cargado de sentido y coherencia, sigue siendo recurrente, como más de treinta años después nos siguen recordando algunos otros autores (Molinero, 2011:5): «el paisaje agrario actual no se entiende sin una mirada al pasado. Es un legado de los grupos humanos que a lo largo de la historia han ocupado un territorio, lo han explotado y lo han organizado; y en cada momento histórico lo han hecho según sus capacidades, intereses y cultura, pero siempre aprovechando las condiciones del medio ecológico. Con el paso del tiempo se ha producido una homogeneización paisajística, por uniformización técnica, que, sin embargo, no ha impedido el mantenimiento de paisajes distintos y dispares, unos vivos, otros que han acabado despareciendo y sólo perviven en el recuerdo, representados en las obras de arte o cantados y evocados por el pueblo».

De manera tal que, en virtud de tales circunstancias este tipo de paisaje termina resultando un «paisaje cultural» en sentido pleno al decir de algunos autores (Hernández, 2009:170): «el paisaje rural es el resultado de la interacción entre la sociedad y el medio en que ésta se asienta...... Nos encontramos, por tanto, ante unos paisajes culturales, resultado de una larga adaptación del hombre al medio en el que se asienta. El paisaje es, por tanto, un concepto complejo, resultado de la combinación de aspectos diversos como son los naturales, los históricos y los funcionales, pero adquiere también valor simbólico y subjetivo al ser considerado reflejo de la herencia cultural de un pueblo, de su identidad y resultado de unas prácticas históricas ejercidas por un grupo humano sobre el territorio». Una valoración como «paisaje cultural» que se ajusta perfectamente al mismo concepto que a este respecto recoge el Consejo de Europa ${ }^{5}$ : «obras culturales de la intervención humana y la naturaleza que ilustran la evolución de la sociedad y su establecimiento a lo largo del tiempo bajo la influencia de las limitaciones físicas y/o las posibilidades que presentan el entorno natural y las fuerzas sociales, económicas y culturales sucesivas, tanto internas como externas».

4. «El espacio rural ha sido colonizado y ordenado por el hombre en épocas diferentes y con unas técnicas de utilización muy variadas. Los paisajes rurales, e incluso agrarios que contemplamos son la expresión de este esfuerzo secular del hombre por poner a su servicio la naturaleza vegetal y animal....Las sociedades rurales han entablado, todas ellas, unas relaciones con la tierra que explotan; relaciones profundas y duraderas, solidificadas por la costumbre y el interés, pero complejas, a causa de la interdependencia, de la imbricación del medio natural y del medio humano. Éstas han creado también unas estructuras agrarias, que se caracterizan, en un conjunto rural dado, por un cierto método de organización del espacio cultivado, de donde resulta un determinado tipo de hábitat, una cierta forma de las parcelas cultivadas, y un particular sistema de cultivo. Todas estas circunstancias, combinadas, se manifiestan en el paisaje agrario» (pg. 1)(este último subrayado y cursiva son nuestros).

5. Council of Europe/Conseil de l'Europe: Cultural Heritage'Thesaurus Hierarchies and alphabetic list of terms in French, English, German and Spanish. European Heritage Network (en http://www.herein-system.eu/core-languages-en-fr-de-es) 
Este valor identitario, muy ligado a la vinculación y lazos afectivos y subjetivos que unen a determinados grupos y sociedades, a los habitantes, con sus diferentes territorios, pone igualmente de manifiesto cuanto de emotivo y personal hay en los distintos tipos de paisaje en un mundo, a su vez, progresivamente más complejo, tal y como muy acertadamente han subrayado algunas investigaciones: «El paisaje comienza a ser considerado reflejo de la herencia cultural de un pueblo, resultado de unas prácticas históricas ejercidas por un grupo humano sobre el territorio. A la dimensión cultural, se une, igualmente, el valor emotivo que se vincula a los paisajes, al ser considerados como signos de identidad frente a la homogeneización y globalización de las dinámicas económicas recientes» (Moltó y Hernández, 2010:262).

Ese afianzamiento que ha ido alcanzando la concepción y entendimiento del paisaje rural como un verdadero paisaje cultural con toda la carga que de ello se deriva ya ha sido puesta de manifiesto en anteriores trabajos, subrayando, así, las imbricadas y estrechas interdependencias no tan directamente visibles, pero sí reconocibles, que lo entretejen y construyen a lo largo del tiempo: «El paisaje es, también, un producto social e histórico moldeado por la población que ocupa, transforma y explota el medio en que se instala, adaptándose a él, en función de un contexto técnico, social e histórico preciso que va evolucionando. En función de esta combinación e interrelación, la sociedad asigna unas funciones al medio, genera una especialización en el proceso de apropiación-ocupación-explotación y le proporciona y otorga una o unas estructura/s y unas formas. Crea, así, en consecuencia, una tipología de formas, de morfologías, que revelan el modelo de ocupación, organización y explotación del espacio, modelo históricamente cambiante. En consonancia con este planteamiento, el paisaje se convierte en un producto «cultural», en el amplio sentido del término (propio de la cultura o forma de entender la ocupación y organización que un determinado grupo social impone en un espacio); el paisaje como un producto ecológico y cultural: «ecocultural», pues» (Plaza, 2009b:136).

Resulta, así, decisivo que subrayemos la verdadera dimensión que tienen estos paisajes rurales como verdaderos «paisajes culturales», lo que le otorga una trascendencia mayor aún y destaca más todavía cuanto de valor patrimonial encierran. Como certeramente se ha escrito, «paisajes, que, por serlo, adquieren su valor patrimonial, es decir, «paisajes patrimonio» o «paisajes patrimoniales»»» (Gómez Mendoza, 2013:6-7).

Y ello es así (la reafirmación de su dimensión patrimonial) porque, en tanto que el paisaje rural puede ser entendido como un totalizador de actuaciones pasadas, constituye un verdadero patrimonio, con la significación que ello tiene de «lo común», «lo que heredamos», como recuerda la definición que del concepto de «patrimonio» proporciona el Consejo de Europa (conjunto de bienes 
heredados del pasado, el patrimonio común) ${ }^{6}$; un producto legado directamente vinculado con un pasado, con un modelo de utilización, de uso, de finalidad determinada que lo ha creado y moldeado. Al decir de Sanz et al. (2010:585), «Los paisajes rurales son expresión territorial de la relación secular de las sociedades humanas con la naturaleza y mantienen, en muchos casos, valores reconocidos.... El reconocimiento de los paisajes como elementos del patrimonio mundial, constituye una oportunidad para algunos paisajes rurales de valor excepcional que, tras una larga trayectoria histórica y productiva, se encuentran hoy amenazados por el abandono de sus funciones tradicionales o la sustitución de las mismas por funciones nuevas que compiten con las anteriores sobre el mismo territorio» (Sanz et al., 2010:585).

En último término, todo ello redunda en esa estrecha relación que existe entre patrimonio y territorio y que se articula o canaliza a través del paisaje, del paisaje rural en este caso. Como en otras publicaciones ya se ha afirmado, «la Europa rural tiene la suerte de poseer un patrimonio natural y cultural extremadamente rico y variado. La gama que ofrece este patrimonio es muy amplia. El futuro de un territorio rural puede depender de su capacidad para utilizar la herencia de su pasado en el momento oportuno. La valorización del patrimonio supone un componente ineludible para el proceso de desarrollo local» ${ }^{7}$. Y a partir de tales considerandos, es necesario añadir que el propio paisaje rural, por su concepción y construcción, tiene un verdadero valor patrimonial. Cada paisaje rural, a su manera, lo hace representando y traduciendo un modo particular y propio de vinculación con el medio y de concepción de organización del espacio, de su explotación y transformación a partir de bases ecológicas, socioeconómicas y técnicas diferenciadas. El mismo concepto de «patrimonio rural» integra a los paisajes junto a otros elementos identificativos materiales e inmateriales ${ }^{8}$.

Podemos señalar, en fin, que el valor patrimonial de los paisajes rurales tiene dos dimensiones o escalas de análisis a través de las que ha de ser entendido. Por un lado, una dimensión o concepción más propiamente global e integradora, que es a su vez identificativa de tipos de paisaje perfectamente catalogados y diferenciados. En este caso entendemos que el propio paisaje rural concreto a que nos referimos y que vemos o catalogamos, definido a partir de unas referencias visuales, morfológicas, estructurales, etc. precisas o determinadas, es todo él en su conjunto (perspectiva global e integradora antes señalada), con todos sus elementos y subunidades que lo forman, un producto gestado, modelado y transformado a lo largo del tiempo, en contextos históricos diferenciados y a partir de estructuras naturales y condiciones socioeconómicas y técnicas distintas, y

6. Council of Europe/Conseil de l'Europe....op. cit.

7. Michael Dower; en LEADER Magazine. Primavera 98 - n. ${ }^{\circ} 17$; pg. 7.

8. Council of Europe/Conseil de l'Europe....op. cit. 
que nos ha sido legado, transmitido, presentando un estado de evolución determinado (el que sea). Algunos de estos paisajes, además, definen perfectamente, mejor que otros, tipos claramente diferenciados e identitarios de ciertas zonas y sistemas («pradería cantábrica», «campos cercados del oeste y noroeste», «paisajes aterrazados mediterráneos», «llanuras cerealistas», etc.).

Por otro lado, existe una visión más sectorial, parcial, analítica, digamos incluso «fragmentaria», por cuanto representa de ruptura con la visión global antes explicada. En este caso argumentamos acerca del valor patrimonial de los paisajes rurales centrándonos en algunos elementos y componentes concretos especialmente significativos, destacados, más sobresalientes, que alcanzan una valoración más singular o específica (ciertos elementos de un patrimonio rural construido - ciertas construcciones de uso agrario, ciertos tipos de caserío o un tipo de poblamiento especial o singular-, algunas infraestructuras agrarias -norias, cigüeñales-, rasgos morfológicos y/o estructurales precisos -la ordenación «geométrica» de un parcelario, la sucesión o gradación altitudinal de ciertos campos o unidades de explotación en una zona montañosa, formaciones boscosas con una ordenación concreta-, etc.). Todos ellos, en este caso, actúan como referentes patrimoniales de esos paisajes en que se insertan.

Pese a todo, este valor patrimonial de los paisajes rurales, de algunos paisajes rurales, no encuentra en todos los casos un reconocimiento institucional como correspondencia, no conoce un proceso de patrimonialización institucional. En muchos de ellos, es el mismo sentimiento y reconocimiento social, colectivo, de la población que lo ocupa y gestiona, el que le otorga tal consideración, produciéndose una identificación entre la sociedad y su paisaje, un sentimiento identitario. $\mathrm{Y}$ en otros casos se dificulta una posible patrimonialización institucional de algunos de estos paisajes, pues la visión o perspectiva con que son oficialmente valorados es defectuosa, sesgada, cuando no claramente miope, ya que preñada y cargada de excesivo ambientalismo, no alcanza a interpretar y comprender correctamente el proceso de construcción de esos paisajes que solo se quieren valorar y patrimonializar atendiendo a sus bases ecológicas o ambientales, limitando severamente de un tiempo a esta parte ciertas ocupaciones y formas de explotación e ignorando que ha sido la comunidad rural o campesina que secularmente ha introducido un determinado modelo de ocupación, uso y organización agraria del espacio a partir de tales ocupaciones -ahora puestas en cuestión- la que lo ha ido moldeando progresivamente, gestionándolo y transmitiéndolo de unas generaciones a otras.

PAISAJES RURALES Y PATRIMONIO RURAL: BASES DE APOYO Y EJEMPLOS CONCRETOS La celebración del XV Coloquio del Grupo de Geografía Rural de la Asociación de Geógrafos Españoles (AGE), que tuvo lugar en Cáceres en el año 2010, puso 
su acento central, precisamente, en esta dimensión sobre la que ahora reflexionamos. Territorio, paisaje y patrimonio se convirtieron en trilogía de referencia $\mathrm{y}$ en lema en torno al que giraron las presentaciones y discusiones mantenidas durante el mismo. La dimensión patrimonial del paisaje y la cada vez mayor incidencia de las investigaciones desarrolladas por la Geografía Rural en esta línea de análisis ha contribuido a reforzar una nueva orientación de los estudios rurales que se basa, precisamente, en la promoción del valor patrimonial de los paisajes y del medio rural, resaltando, al mismo tiempo, la elevada potencialidad estética y ambiental de los mismos y la función tan decisiva que han venido desempeñando la gestión y potenciación de esta estrecha relación en el desarrollo de estos territorios.

\section{La apoyatura de contexto: fundamentos, referencias y contextos normativos y documentales en que se recogen estas orientaciones}

El marco o ámbito en que cobra cada vez más importancia el valor patrimonial del paisaje, y del paisaje rural en particular, viene definido por planteamientos de referencia y relación a partir de los que este vínculo se hace cada vez más explícito. Planteamientos que quedan recogidos en textos normativos y documentales muy diversos, de reciente puesta en marcha, pero también en «filosofías» y lógicas de entendimiento del mundo y el medio rural (¿qué futuro para el mundo rural?; las nuevas ruralidades; el desarrollo sostenible; la multifuncionalidad; etc.) que empiezan a desarrollarse a través de iniciativas y programas en el último decenio del pasado siglo xx en la Unión Europea, también en España, lógicamente.

El Consejo de Europa ha sido, en este sentido, una institución pancontinental que ha desempeñado un papel de primer orden. En su seno se produjo la elaboración y aprobación, en el año 2000, del Convenio Europeo del Paisaje, lo que constituyó, en tal sentido, un hecho decisivo. La puesta en marcha del mismo y su posterior desarrollo normativo y operativo aplicado en los distintos Estados europeos que lo ratifican e incorporan a su gestión y ordenación del territorio han generado una nueva atención, observación y valoración de los paisajes rurales. Es en este Convenio donde se declara explícitamente que el paisaje es un componente fundamental del patrimonio cultural y natural. Y fue también en el Consejo de Europa donde las políticas de definición e impulso al patrimonio, muy especialmente al patrimonio cultural, sentaron las bases para avanzar más en esta dimensión y vincularla muy estrechamente con la noción de paisaje y sus diferentes tipos.

En el marco eurocomunitario, el de la Unión Europea, encontramos otros dos apoyos de primer orden que explican, igualmente, el auge otorgado a las relaciones entre el paisaje rural y su valor patrimonial tan destacado. Así, 
desde los años 90, la progresiva implantación y extensión espacial de iniciativas especificamente dirigidas al desarrollo rural, especialmente la iniciativa comunitaria LEADER (complementada en España, con posterioridad, por los programas PRODER), abonaron ya el terreno que condujo progresivamente a una revalorización patrimonial y ambiental de los paisajes rurales. El patrimonio natural, el patrimonio cultural y los paisajes rurales trenzaron una de las medidas específicas impulsadas con fondos comunitarios para la revalorización de estos territorios. Estas iniciativas y programas, a su vez, se han apoyado también en el conjunto de orientaciones que han marcado su ejecución: las Directrices Estratégicas de Desarrollo Rural. Una de las prioridades comunitarias para el desarrollo rural en el último periodo ya finalizado (el 2007-2013) y recogida en tales orientaciones (estas Directrices), concretamente el segundo eje de la política de desarrollo rural de la UE, ha sido, precisamente, la mejora del medio ambiente y del paisaje rural, ayudando a la gestión territorial. Desde los «considerandos» iniciales de tales Directrices, se marca claramente el camino a seguir: «Estas directrices estratégicas deberían reflejar el papel multifuncional que desempeña la actividad agraria en la riqueza y diversidad de los paisajes, de los productos alimenticios y del patrimonio cultural y natural en toda la Comunidad......En numerosas zonas, estos paisajes constituyen un elemento importante del patrimonio cultural y natural y es lo que hace que constituyan zonas atractivas para vivir y trabajar» [DECISIÓN DEL CONSEJO de 20 de febrero de 2006 sobre las directrices estratégicas comunitarias de desarrollo rural (período de programación 2007-2013)(2006/144/CE)-Diario Oficial de la Unión Europea de 25.2.2006].

A escala nacional, en España ha tomado impulso y carta de naturaleza el paisaje rural y los valores patrimoniales que encierra a partir de tres referencias fundamentalmente. Por una parte, dos nuevos textos normativos que fueron aprobados en el mismo mes y año (diciembre de 2007), la Ley del patrimonio natural y la biodiversidad y la Ley para el desarrollo sostenible del medio rural. En la primera de ellas, junto al paisaje y el patrimonio como conceptos centrales, se introdujo novedosamente el concepto de «custodia del territorio», entendida en el propio articulado de la ley (art. ${ }^{\circ}$ 3.9.) como «conjunto de estrategias o técnicas jurídicas a través de las cuales se implican a los propietarios y usuarios del territorio en la conservación y uso de los valores y los recursos naturales, culturales y paisajísticos». Por su parte, la Ley para el desarrollo sostenible del medio rural deja, asimismo, muy claro desde el principio (art. ${ }^{\circ}$ 2.1.c) que uno de sus objetivos es el de «conservar y recuperar el patrimonio y los recursos naturales y culturales del medio rural», reforzándolo más adelante, al hablar de la planificación ambiental, con el hecho de que «se considerarán, específicamente, las actuaciones ligadas al mantenimiento y protección de los paisajes protegidos y de interés del medio rural y las áreas de montaña. Se incluirán iniciativas para 
el conocimiento, protección y uso sostenible del patrimonio geológico, minero y biológico como recurso científico, cultural y turístico» (art. $\left.{ }^{\circ} 19\right)$.

Junto a estos dos marcos normativos, resulta, finalmente, de indudable valor para el entendimiento del paisaje y el patrimonio rural, aunque ya en otro orden de consideración, la Carta de Baeza sobre el patrimonio agrario (2012). No constituye un texto legal ni vinculante, pero sí es producto de un trabajo de reflexión y debate conjunto e interdisciplinar desarrollado en el seno de una prolongada investigación que culminó en un seminario específico celebrado en Baeza (Jaén) y en cuyo ámbito se redactó y aprobó este documento. Se concibe, pues, más como un marco orientativo y muy acorde en el que resaltar este binomio de paisaje rural y valor patrimonial del mismo. La Carta constata, desde un primer momento, «la relevancia y significación de los valores culturales y naturales que tienen los bienes agrarios, así como su correspondencia con algunas de las formas patrimoniales y significados más avanzados del Patrimonio Cultural y Natural: su dimensión territorial, la presencia de bienes naturales y culturales, etc.» (Castillo Ruiz, 2013:28) y considera al paisaje rural, desde la perspectiva de su valor patrimonial y circunscribiéndolo a los bienes integrantes que intervienen para definir el patrimonio agrario, de un modo cuando menos singular, entendiéndolo como un «bien inmueble de conjunto o lineal»

\section{El valor patrimonial de algunos paisajes rurales tomados como ejemplos}

No encontramos mejor forma de concluir todas estas argumentaciones y reflexiones que aquí se han explicado que recurriendo a estudios de caso que, muy brevemente presentados y descritos, nos sirvan de ejemplo representativo de estos planteamientos, intentando concretarlos de forma más práctica.

Un primer ejemplo en que podemos detenernos, por cercanía y conocimiento, es el de los paisajes de campos cercados de las penillanuras del occidente de Castilla y León, especialmente extendido por algunas comarcas del oeste zamorano (Aliste y Sayago sobre todo; algo menos presentes -aunque también- en La Carballeda y en áreas muy dispersas de Sanabria), que sin embargo también se distribuye por las penillanuras salmantinas y extremeñas, así como por diferentes áreas y comarcas del interior de Galicia, aunque en este último caso ya con diferencias. Es un paisaje rural que, aun sin gozar de una patrimonialización que traduzca ese reconocimiento institucional que sí tienen otros, sin embargo constituye un paisaje identitario para la comunidad rural que se apoya en la singularidad que va unida al proceso de configuración llevado a cabo desde hace bastante tiempo por ese colectivo humano que ha ocupado estas comarcas, modelándolo, gestionándolo y ordenándolo.

Ha sido denominado de muy distintas maneras: la arquitectura de piedra, los paisajes de la piedra seca, los paisajes del cortineo o cortiñedo, cerramientos, 
paisaje de campos cercados o cerrados, paisaje de prados murados, herreñales....Por encima de todas ellas, e independientemente de la ocupación del suelo que albergan (cultivo, prado, viñedo, etc.), aparece un elemento que identifica a este paisaje y que está presente en esos distintos nombres con que es conocido y se le han dado: las cercas de piedra que, sin argamasa alguna («piedra seca») y no superando normalmente la altitud de $1 \mathrm{~m}$ ó $1,25 \mathrm{~m}$, delimitan las parcelas o campos de muy contrastado tamaño.

Es, pues, un referente morfológico muy preciso y visible el que otorga un valor patrimonial específico a este paisaje: una determinada morfología, un parcelario fragmentado, formado por campos que, a modo de teselas o piezas de un puzzle muy diferenciado, ordenan una parte muy importante del espacio agrario de los distintos términos municipales y que se sustancia en un material con el que se construye, como es la roca propia de la zona, bien granito, bien pizarra. Ambos (morfología y material), son la base sobre la que se sustancia la interpretación y explicación del valor patrimonial que tiene el paisaje así construido. De tal manera que a partir de ellos, una correcta interpretación de este paisaje nos llevaría a distinguir distintas referencias y/o maneras de acercarnos a su conocimiento y estudio:

- la contextualización: territorial (comarcas y espacios por los que se extiende y relación con ellos, situación fronteriza y reproducción de similar paisaje al otro lado de la «raya» hispanolusa), agraria o funcional (vinculación con usos específicos), paisajística (penillanuras de orientación ganadera) e histórica (relación con la propiedad y los usos colectivos o comunales);

- las cercas que le definen -elemento morfológico y construido que es «central» en la definición e identificación de este paisaje- y la variada tipología a la que responden (según su situación; según su tamaño; según el material con el que se han levantado; según su forma o trazado; según el contenido y ocupación que encierran; e incluso según estén o no acompañadas de arbolado); es ésta, podríamos decir, una «escala micro» o de detalle (Fig. 1 y 2);

- la configuración del paisaje que introducen estos campos cercados: una ordenación geométrica variada que, a modo de red de desigual extensión y trazado, estructura el terrazgo agrario del término municipal a partir de los núcleos de población y adoptando formas muy distintas (una «escala macro» o más amplia, del conjunto)(Fig. 3 y 4);

- y también, como valor patrimonial inmaterial asociado a este tipo de paisaje rural, los términos y el lenguaje que designa tanto a este paisaje como a las unidades que se distinguen en él y a los materiales y los 
elementos diferenciados que lo construyen («cortina», «herreñal», «hincón» o «fincón», «arrimaderos», «jejos», «albañales», etc.).

A todas estas referencias han de unirse, además, las valoraciones perceptuales y sensoriales que tienen como indicativo central a los colores y los tonos generados por las distintos usos y diferentes ocupaciones del suelo (prados, cultivos, matorrales, arbolado), variables igualmente según la época del año.

Y es también un paisaje secular que, estudiado por algunos de nuestros más señeros maestros de la Geografía española (García Fernández, Cabo Alonso), aunque también ha concitado el interés y atracción investigadora de historiadores, ya aparece perfectamente documentado en las respuestas del Catastro del Marqués de la Ensenada ${ }^{9}$ e incluso, tal y como el profesor García Fernández recogía ya en su texto (1966:117), y basándose en el trabajo anterior del profesor Cabo Alonso (1956), aparecen ya desde una época temprana que remonta hasta el siglo XII, pese a que no es menos cierto, siguiendo estas aportaciones indicadas, que una parte importante de este paisaje de campos cercados que actualmente conocemos es más bien producto de épocas más recientes, coincidentes con la desaparición progresiva de la propiedad colectiva. Este paisaje patrimonial es, pues, un verdadero producto social e histórico, de ese proceso histórico que en páginas anteriores se señalaba como un referente también específico del valor patrimonial de los paisajes rurales.

Un segundo ejemplo que podemos tomar también como referencia es el de los paisajes abancalados o aterrazados de las Arribes del Duero, un tipo de paisaje que singulariza muy especialmente a este espacio «rayano» o fronterizo y que se extiende por el suroeste de la provincia de Zamora y el noroeste y oeste de la provincia de Salamanca, limítrofes con el nordeste portugués (Beira Interior Norte, Alto Douro/Douro Superior). Es, pues, uno de los paisajes más característicos de la «raya» hispano-portuguesa. A diferencia del anterior, hay dos hechos distintivos que le identifican: es un paisaje donde domina más la orientación agrícola y no tanto ganadera (aunque con contrates) y sí goza de una patrimonialización institucional por su integración en el Parque Natural Arribes del Duero

9. Así, por ejemplo, a la cuarta pregunta de estas Respuestas Generales (Qué especies de tierra se hallan en el término; si de Regadio y de Secano, distinguiendo si son de Hortaliza, Sembradura, Viñas, Pastos, Bosques, Matorrales, Montes, y demás, que pudiere haber, explicando si hay algunas que produzcan más de una cosecha al año, las que fructificaren solo una, y la que necesitan de un año intermedio de descanso), responden los pueblos reseñando la existencia de este tipo de unidades. En Figueruela de Arriba se indica expresamente «...cortinas muradas, producen todos los años»; en Gallegos del Campo «...cortinas muradas, producen sin intermisión»; en Riomanzanas «....prados murados, producen sin intermisión». Como puede observarse, en las respuestas se distingue perfectamente «cortinas» (ocupación con cultivo) de «prados» (hierba para el ganado), ambos «murados», es decir, cercados o cerrados con un muro - de piedra-. 
(106.500 has), continuado del lado portugués por el Parque Natural Douro Internacional. Sin embargo, los principales referentes que han conducido a la patrimonialización institucional de este espacio no han sido tanto los del paisaje rural tan singular que le define, como más bien los ligados al patrimonio natural (encajamiento del río Duero y configuración de un profundo $\mathrm{y}$ prolongado «cañón», singularidad de especies vegetales y de fauna, así como la localización de ciertos lugares de excepcional belleza ligados a ciertos pozos y cascadas -«caideros»-vertientes al Duero).

Ha sido, asimismo, un paisaje igualmente secular en su prolongada construcción a lo largo del tiempo, muy ligado a los esfuerzos espectaculares que estas comarcas y comunidades agrarias tan periféricas en sus respectivas regiones y países, en su adaptación a unas condiciones de relieve tan limitantes, han ido realizando históricamente, y muy unido, asimismo, a un contexto de economías de subsistencia largamente prolon-

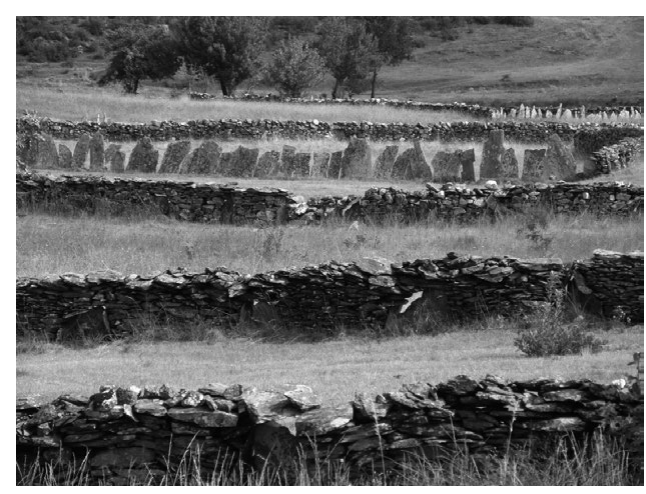

Figura 1. Sucesión de campos cercados al E de la localidad de Mellanes (término municipal de Rabanales, comarca de Aliste) Fotografía del autor (3-09-2015).

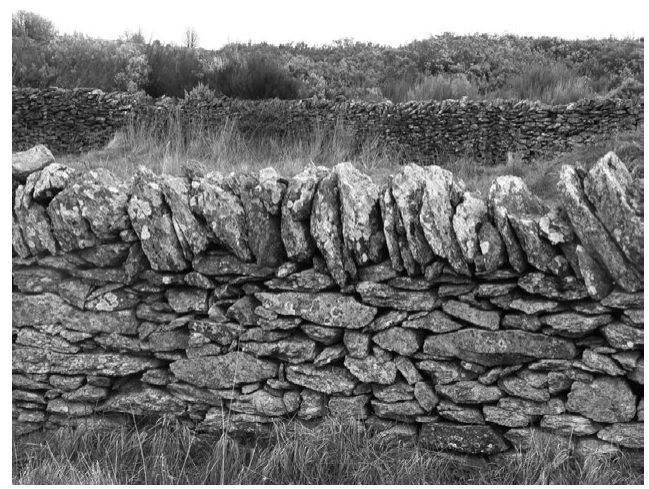

Figura 2. Detalle de la cerca de un «prado murado» en la localidad de Sandín (comarca de La Carballeda). Fotografía del autor (24-04-2015). gadas en estas áreas y objeto de investigación a través de excelentes monografías (Crespo Redondo, 1968) y de trabajos más recientes (Molinero et al., 2013). También ha sido un paisaje que concitó el interés de intelectuales como Miguel de Unamuno, quien publicó en 1905 la obra Los Arribes del Duero (Notas de un viaje por la raya de Portugal ilustradas con 15 fotografias), en la que rendía cuenta de un viaje realizado a esta zona, conocida durante mucho tiempo como «La Ribera», con unos amigos en 1902.

El valor patrimonial esencial que identifica a este paisaje rural a uno y otro lado del Duero fronterizo viene definido también por una doble consideración: 


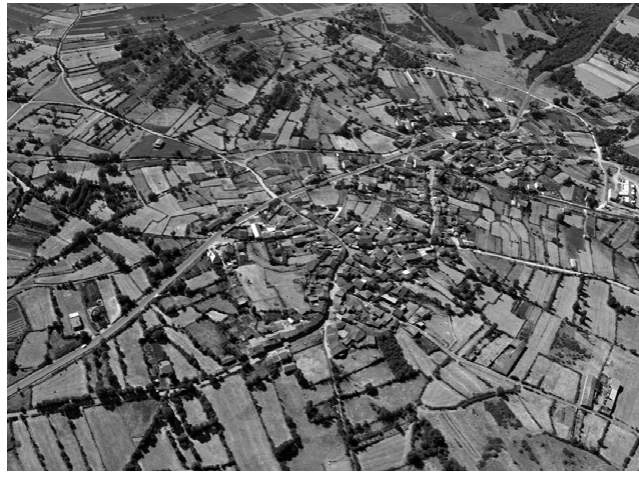

Figura 3. Configuración morfológica del parcelario agrario en torno al pueblo de San Vitero (comarca de Aliste), constituida por la red de campos cercados dispuestos de forma concéntrica en torno al núcleo de población (Fotografía: Eugenio Baraja, 19-07-2015).

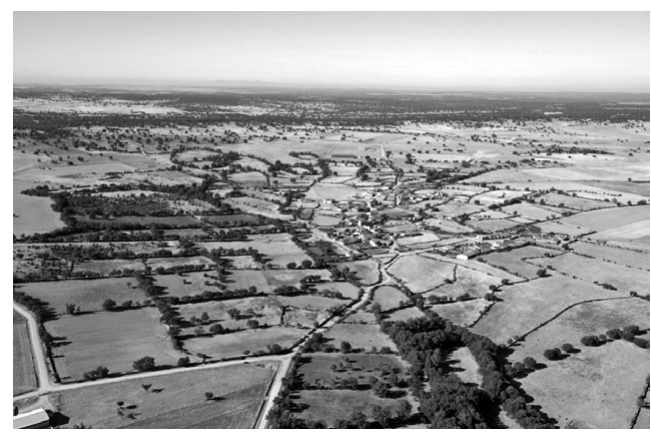

Figura 4. Disposición alargada de la red de campos cercados que se extienden al norte de la localidad de Escuadro (comarca de Sayago)

(Fotografía: Eugenio Baraja, 19-07-2015).
- la ordenación espacial y los elementos morfológicos, referencias ambas que traducen la fuerte influencia que ejerce en su construcción y configuración el pronunciado relieve de las pendientes creado por la entalladura tan profunda del río Duero sobre la penillanura granítica;

- y las particulares condiciones microclimáticas que tal encajamiento genera en la zona, lo que facilita el desarrollo de cultivos más termófilos y mediterráneos (almendro, olivo, naranjos, etc.) que los de la penillanura que a uno y otro lado bordea las Arribes o que, cuando menos, favorecen su mayor asentamiento y mejor profusión (el viñedo).

Todo ello se traduce en la configuración de un paisaje muy mediterraneizado, que guarda gran mimetismo con el de los aterrazamientos de algunas montañas levantinas (siendo estas terrazas o «bancales» construidas por el hombre como respuesta adaptativa a las duras pendientes para retener el suelo el elemento agrario construido que adquiere referencia central), donde los elementos y componentes que refuerzan ese valor patrimonial señalado y a través de los cuales se puede proceder a una mejor y más completa interpretación y entendimiento del propio paisaje son muy precisos (Fig. 5 y 6 ):

- un elemento lineal central en torno al que se configuran los elementos del paisaje: el río Duero (o el curso bajo del río Águeda, afluente del Duero, en los Arribes más meridionales);

- un gradiente vertical en la ordenación del terrazgo agrícola que viene determinado por el escalonamiento o aterrazamiento de las vertientes 
a través de la construcción de «bancales»;

- un gradiente horizontal definido por la disposición lineal, paralela a la de las curvas de nivel, que presenta la distribución ordenada de los cultivos que ocupan los bancales y que proporciona una imagen bastante uniforme;

- una disposición geométrica contrastada definida por los distintos grupos de cultivos que se distribuyen bien en los bancales o bien a lo largo y ancho de las lomas y cerros en que se degrada el relieve en aquellas zonas donde se suaviza la tiranía de las pendientes, generando una imagen que se asemeja a una distribución de polígonos de diferentes contornos y tamaños que albergan diferentes cultivos;

- el variado colorido que impregnan esos distintos cultivos al propio paisaje

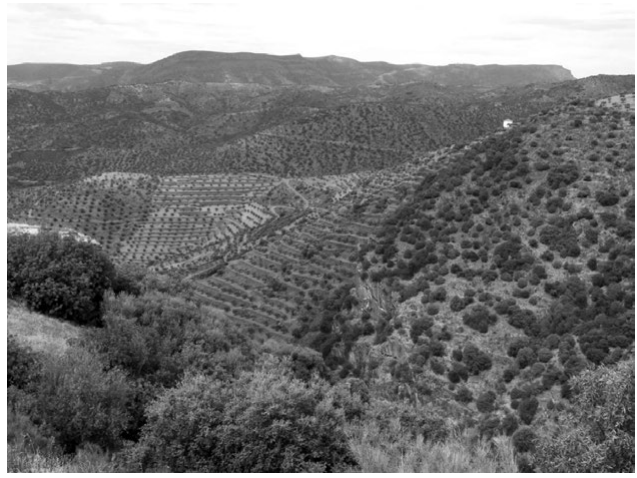

Figura 5. Paisaje agrario de las Arribes del Duero en el sector próximo a Barca d'Alva y Vega Terrón (Fotografía del autor, 12-6-2015).

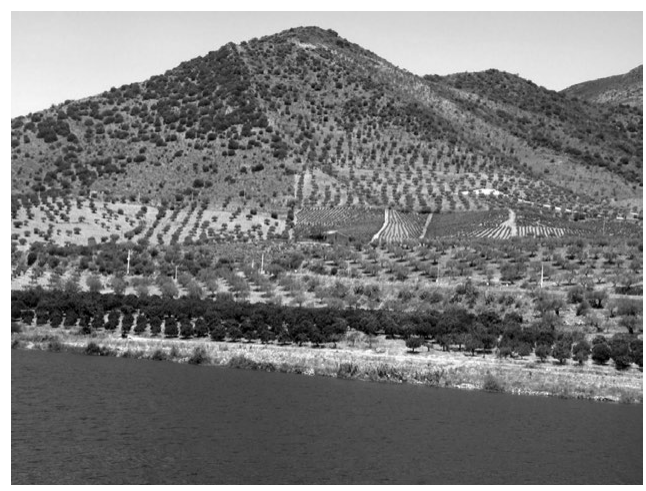

Figura 6. Ordenación vertical y horizontal de usos y aprovechamientos en las vertientes junto al río Duero en la frontera hispanolusa (Vega TerrónBarca d'Alva)(Fotografía del autor, julio 2008). y refuerzan su diversidad sensorial, donde predomina el color verde pero de muy distintos tonos según sea el del olivo, el del naranjo, el del viñedo o el de otros frutales;

- e intercalado y disperso entre todo este mosaico de elementos que ordenan el terrazgo y proporcionan la imagen del paisaje rural, aparece la morfología granítica a través de micro y mesoformas de muy distintos contornos y modelados (yelmos, berruecos, vertientes convexas....) que define el armazón físico de este espacio y las construcciones para el aprovechamiento hidroeléctrico (sucesivas presas dispuestas escalonadamente a distintas cotas a lo largo del curso fronterizo del Duero en este borde fronterizo) para el que reúne condiciones muy propicias. 
Un paisaje que, sin embargo, presenta muy distinto grado de conservación y gestión según miremos para el lado portugués, donde aún hay una mayor intensidad y presencia del cuidado y laboreo de los bancales y de los viñedos, o para el lado español, donde ha progresado mucho más el abandono y la desestructuración.

Ejemplos, en definitiva, los de estos dos estudios de caso muy brevemente presentados que sirven para constatar de forma práctica y más adecuada el argumento central (el valor patrimonial de los paisajes rurales) que hemos querido desarrollar a lo largo de estas páginas escritas en homenaje muy querido a uno de los maestros de la Geografía española que tanto ha enseñado, precisamente, sobre los paisajes y usos agrarios y a tantas promociones de estudiantes y geógrafos ha formado, el profesor Alfredo Morales Gil.

\section{BIBLIOGRAFÍA}

Barrientos Alfageme, G. (2010): «Aproximación al concepto y la tipología del patrimonio rural», en Leco, F; Pérez, A. y Mateos, A.B. (coords.): XV Coloquio de Geografia Rural. Geografía y Desarrollo Rural. Territorio, Paisaje y Patrimonio. Ponencias, Ministerio de Medio Ambiente y Medio Rural y Marino-Confederación Hidrográfica del Guadiana, Cáceres, pp. 93-109.

Cabo Alonso, A. (1956): «El colectivismo agrario en Tierra de Sayago». Estudios Geográficos, n. ${ }^{\circ} 65$, pp. 593-658.

Castillo Ruiz, J. (Dir.)(2013): Carta de Baeza sobre Patrimonio Agrario. Universidad Internacional de Andalucía. Sevilla. 72 pp.

Crespo Redondo, J. (1968): El paisaje agrario en los Arribes del Duero, Consejo Superior de Investigaciones Científicas, Instituto «Juan Sebastián Elcano», Madrid, $148 \mathrm{pp}$.

FERIA TORIBIO, J.M. a (2013): «El patrimonio territorial: algunas aportaciones para su entendimiento y puesta en valor», en e-rph. Revista electrónica de patrimonio histórico, $\mathrm{n}^{\circ}$ 12, $25 \mathrm{pp}$.

FERNÁNDEZ CACHO, S. et al. (2010): «El paisaje y la dimensión patrimonial del territorio. Valores culturales de los paisajes andaluces», en VI Congreso Internacional de Musealización de Yacimientos y Patrimonio. Arqueología, Patrimonio y Paisajes Históricos para el siglo XXI. Ponencias. Toledo, pp. 59-73.

García Fernández, J. (1966): «Campos abiertos y campos cercados en Castilla la Vieja», en Homenaje al Excmo. Sr. D. Amando Melón y Ruiz de Gordejuela. Zaragoza, Instituto de Estudios Pirenaicos, pp. 117-131.

Gómez MendozA, J. (2013): «Del patrimonio paisaje a los paisajes patrimonio», en Documents d'Anàlisi Geogràfica, vol. 59/1, pp. 5-20.

Hermosilla Pla, J. e Iranzo García, E. (2004): «El patrimonio rural como factor de desarrollo endógeno», en Saitabi, n. ${ }^{\circ}$ 54, pp. 9-24.

HERNÁNDEZ HERNÁNDEZ, M. (2009): «El paisaje como seña de identidad territorial: valorización social y factor de desarrollo, ¿utopía o realidad?», en Boletín de la Asociación de Geógrafos Españoles, n. ${ }^{\circ} 49$, pp. 169-183. 
Mata Olmo, R. (2004): «Agricultura, paisaje y gestión del territorio», en Polígonos. Revista de Geografía, $n .^{\circ} 14$, pp. 97-137.

Mata Olmo, R. (2010): «La dimensión patrimonial del paisaje. Una mirada desde los espacios rurales». En Maderuelo, J. (ed.): Paisaje y Patrimonio. Centro de Arte y Naturaleza (CDAN)-Abada Editores, Huesca, pp. 31-73.

Molinero Hernando, F. (2011): «Paisajes y economías agrarias: del policultivo de subsistencia a la especialización agraria mundial»; en Leco Berrocal, F.; Pérez Díaz, A. y Mateos Rodríguez, B. (coords.): XV Coloquio de Geografía Rural. Geografía y Desarrollo Rural. Territorio, Paisaje y Patrimonio. Ponencias, Ministerio de Medio Ambiente y Medio Rural y Marino-Confederación Hidrográfica del Guadiana, Cáceres, 2011; pp. 5-56.

Molinero Hernando, F.; Ojeda Rivera, J.F. y Tort Donada, J. (Coords.)(2011): Los paisajes agrarios de España. Caracterización, evolución y tipificación; Ministerio de Medio Ambiente y Medio Rural y Marino; Madrid. 606 pp.

Molinero Hernando, F.; Alario Trigueros, M. y Cascos Maraña, C. (2013): «El paisaje de la «raya» de Portugal en Castilla y León: un espacio de frontera contrastado y singular», en Actas del XXIII Congreso de Geógrafos Españoles: Espacios insulares y de frontera, una visión geográfica, Palma de Mallorca, pp. 165-176.

Moltó Mantero, E. y Hernández Hernández, M. (2010): «El paisaje y las iniciativas de desarrollo rural. Luces y sombras», en Leco, F; Pérez, A. y Mateos, A.B. (coords.): XV Coloquio de Geografía Rural. Geografia y Desarrollo Rural. Territorio, Paisaje y Patrimonio Rural. Comunicaciones, Universidad de Extremadura-Servicio de Publicaciones, Cáceres, pp. 261-271.

Ose (2009): Patrimonio natural, cultural y paisajístico. Claves para la sostenibilidad. http://www.sostenibilidades.org/Observatorio+Sostenibilidad/esp/PubInd/ Tematicos/Patrimonio/

Plaza Gutiérrez, J.I. (2009a): «Nuevos territorios y nuevos desarrollos en las áreas rurales. Conservación, patrimonio, biodiversidad, paisaje», en Observatorio Medioambiental, vol. 12, pp. 9-14.

Plaza GutiÉrrez, J.I. (2009b): «El paisaje de Aliste y Tras-Os-Montes, producto de las interrelaciones sociedad y territorio», en Actas III y IV Congreso de Antropología de España y Portugal, Instituto de Estudios Zamoranos «Florián de Ocampo»Diputación de Zamora, Zamora, pp. 135-151.

Prada Llorente, E. (2004): «El paisaje como archivo del territorio». Cuadernos de Investigación Urbanística, n. ${ }^{\circ}$ 40, pp. 9-65.

Prada Llorente, E. (2005): «Paisaje agrario: antropología de un territorio». Ciudad y Territorio. Estudios Territoriales, n. ${ }^{\circ}$ 144, pp. 343-372.

Prada Llorente, E. (2009): «El hombre y el paisaje. Guía para una comprensión integral del paisaje agrario», en Actas III y IV Congreso de Antropología de España y Portugal, Instituto de Estudios Zamoranos «Florián de Ocampo»-Diputación de Zamora, Zamora, pp. 81-91.

Puente Fernández, L. de la (2010): «El Patrimonio Rural y su protección», en Leco, F; Pérez, A. y Mateos, A.B. (coords.): XV Coloquio de Geografia Rural. Geografia 
y Desarrollo Rural. Territorio, Paisaje y Patrimonio Rural. Comunicaciones, Universidad de Extremadura-Servicio de Publicaciones, Cáceres, pp. 477-488.

Rubio Terrado, P. (2010): «El patrimonio rural», en Leco, F; Pérez, A. y Mateos,

A.B. (coords.): XV Coloquio de Geografía Rural. Geografia y Desarrollo Rural. Territorio, Paisaje y Patrimonio. Ponencias, Ministerio de Medio Ambiente y Medio Rural y Marino-Confederación Hidrográfica del Guadiana, Cáceres, pp. 111-177.

Ruiz UrRestarazu, E. (2001): «Patrimonio rural y políticas europeas», en Lurralde, n. ${ }^{\circ} 24$, pp. 305-314.

Sanz Herráiz, C.; Molina Holgado, P. y López Estébanez, N. (2010): «Patrimonio cultural y medio ambiental en paisajes rurales», en Leco, F; Pérez, A. y Mateos, A.B. (coords.): XV Coloquio de Geografía Rural. Geografía y Desarrollo Rural. Territorio, Paisaje y Patrimonio Rural. Comunicaciones, Universidad de Extremadura-Servicio de Publicaciones, Cáceres, pp. 585-597.

Silva PÉrez, R. (2009): "Agricultura, Paisaje y Patrimonio Territorial. Los paisajes de la agricultura vistos como patrimonio», en Boletín de la Asociación de Geógrafos Españoles, n. ${ }^{\circ}$ 9, pp. 309-334.

VV.AA. (2000): Guía para la puesta en valor del patrimonio del medio rural. Junta de Andalucía-Empresa Pública para el Desarrollo Agrario y Pesquero de Andalucía. Córdoba. 344 pp.

Zoido Naranjo, F. (2004): «El paisaje. Patrimonio público y recurso para la mejora de la democracia», en $\mathrm{PH}$, Boletín del Instituto Andaluz de Patrimonio Histórico, n. ${ }^{\circ}$ 50, pp. 66-73. 